\title{
O Sistema Nacional de Armas (Sinarm) como Sistema de Gerenciamento do Estoque Legal de Armas no Brasil: Uma Contribuição às Políticas Públicas
}

\author{
Francisco Fonseca ${ }^{1}$, Ruben Keinert ${ }^{2}$, Izidoro Blikstein $^{3}$ \\ Luciano Bueno ${ }^{4}$, Fabio Storino, ${ }^{5}$ Hironobu Sano ${ }^{6}$
}

RESUMO: Este artigo analisa os resultados de uma pesquisa, realizada em 2005, selecionada, por meio de concurso público, pela Secretaria Nacional de Segurança Pública (Senasp/Ministério da Justiça), sobre o funcionamento do Sistema Nacional de Armas (Sinarm) como instrumento de gestão de informações sobre o estoque legal de armas de fogo. Objetiva compreender como o Sinarm - que teve sua importância aumentada em razão da vitória do "não" à proibição do comércio de armas e munições no referendo ocorrido em 2005 pode contribuir para a existência de políticas públicas de Segurança Pública e particularmente sua eficácia como sistema de controles e gerenciamento do estoque de armas legais no Brasil. São exploradas suas interfaces com as políticas públicas de segurança, com a ausência de uma "cultura de controles” no Brasil, e com as múltiplas causas das mortes com armas de fogo, entre outras. Como subsídio a este artigo, a pesquisa comparou o Sinarm com sistemas análogos em outros países, analisou a legislação, realizou entrevistas com autoridades e técnicos gestores do sistema e, sobretudo, observou in loco o funcionamento do Sinarm. Concluiu-se que sua criação implicou avanços, que sua operação é simples, mas pouco confiável e segura, mas que há formas de suplantar tais dificuldades, pois fundamentais à existência de políticas de segurança.

PALAVRAS-CHAVE: SINARM; armas de fogo; políticas públicas; violência; segurança pública.

ABSTRACT: This article analyzes the results of research carried out in 2005 on the functioning of the National Arms System as an instrument for management of information on legal possession of firearms. The research won a competitive grant from the National Secretariat of Public Security (SENASP/ Ministry of Criminal Justice.) It seeks to understand how the SINARM - an entity whose importance increased as a result of the "NO" victory on a national gun control referendum that was conducted in 2005 - can contribute to the existence of public policies for Public Security and particularly, its own efficiency as a system for control and management of legally-owned arms and weapons in Brazil. We look at its connections to public safety policies, to the absence of a "culture of control" in the country and to the multiple causes of deaths by firearms. To lend support to our argument, the research compared the SINARM to analogous systems in other

\footnotetext{
${ }^{1}$ Docente da Escola de Administração de Empresas de São Paulo Fundação Getulio Vargas

${ }^{2}$ Docente da Escola de Administração de Empresas de São Paulo Fundação Getulio Vargas

${ }^{3}$ Docente da Escola de Administração de Empresas de São Paulo Fundação Getulio Vargas

${ }^{4}$ Doutorando da Escola de Administração de Empresas de São Paulo Fundação Getulio Vargas

${ }^{5}$ Doutorando da Escola de Administração de Empresas de São Paulo Fundação Getulio Vargas

${ }^{6}$ Doutorando da Escola de Administração de Empresas de São Paulo Fundação Getulio Vargas

Endereço para correspondência: FSJ - Av 9 de Julho 2029 cep 01313-902 - Bela Vista .São Paulo
} 
countries, analyzed legislation, carried out interviews with authorities and technicians who manage the system and above all, carried out in loco observation on the way the SINARM works. We conclude that its creation meant progress and that its operation is simple but not particularly reliable or secure; nonetheless, we also maintain that there are ways to deal with such difficulties, since the entity is crucial to the existence of public security policies.

KEYWORDS: SINARM, firearms, public policies, violence, public safety. 


\section{Introdução}

Este artigo analisa os resultados de uma pesquisa realizada e finalizada em 2005, sob o patrocínio da Secretaria Nacional de Segurança Pública (Senasp), órgão do Ministério da Justiça, sobre o funcionamento do Sistema Nacional de Armas (Sinarm). Tratou-se de um concurso público que selecionou projetos com o objetivo de diagnosticar e propor alternativas na área de gestão em Segurança Pública.

Por meio da comparação com sistemas de controles de armas de outros países, da análise da legislação, da realização de entrevistas com autoridades e técnicos gestores do sistema em Brasília e em algumas localidades importantes e, sobretudo, da observação in loco do Sinarm, a pesquisa procurou mapear os avanços, fragilidades e dificuldades deste sistema de gerenciamento de dados sobre armas, que fora criado apenas em 1997 pela Polícia Federal (PF) e desde então por ela gerenciado.

Dessa forma, este artigo objetiva compreender como o Sinarm - que teve sua importância aumentada em razão da vitória do “não” à proibição do comércio de armas e munições no referendo ocorrido em 2005 - pode contribuir para a existência de políticas públicas na área de Segurança Pública e particularmente observar sua eficácia como sistema de controles e gerenciamento do estoque de armas legais no Brasil. Neste artigo, apenas tangenciaremos a comparação com os sistemas de outros países.

Por fim, embora o foco central seja o modelo gerencial do Sinarm, foram exploradas suas interfaces: com a questão das políticas públicas de segurança; com a ausência de uma “cultura política de controles” no Brasil; com o contexto maior da violência; entre outras. Com isso, espera-se que, por meio da análise do Sinarm, seja possível compreender determinados processos de gerenciamento voltados à maior eficácia da Administração Pública.

\section{Metodologia}

Basicamente, a metodologia da pesquisa pode ser assim resumida: comparou-se o Sinarm com sistemas análogos em outros países; foram analisadas as legislações existentes e criadas a partir do Estatuto do Desarmamento; foram realizadas entrevistas com autoridades e técnicos gestores do sistema em Brasília, São Paulo, Presidente Prudente, Campinas e Foz 
do Iguaçu - todas essas cidades, por razões diferentes, são estratégicas e dão uma amostra do modus operandi do Sinarm - e também se observou in loco o funcionamento do Sinarm. Por fim, procurou-se contextualizar as observações in loco com a literatura existente, sobretudo o conhecimento acerca do papel das instituições brasileiras, notadamente policiais e judiciárias, e das conexões entre violência e ambiente social, econômico e cultural do País.

\section{A Gênese do Sinarm}

O Projeto de Lei 64/1996, originado na Câmara dos Deputados, suscitou discussões que culminaram na Lei 9.437, de 20 de fevereiro de 1997; esta criou o Sistema Nacional de Armas - Sinarm. A lei também estabeleceu as condições para o registro e o porte de armas de fogo, e definiu crimes decorrentes de sua desobediência. A primeira versão do Sinarm (software) foi desenvolvida internamente pelo Centro de Tecnologia da Informação (CTI) da Polícia Federal e entrou em operação ainda em 1997. Já no Senado, a partir do Projeto de Lei 292/1999 iniciaram-se as discussões sobre o Estatuto do Desarmamento, que culminou na Lei 10.826/2003 (que regula o Estatuto).

Os estados da federação passaram a enviar as informações ao Sinarm em 2001. Até o início de agosto de 2005, o Sinarm tinha cerca de três milhões de armas cadastradas. Os maiores estados, segundo o número de registro de armas, são: São Paulo, Rio Grande do Sul, Pernambuco, Rio de Janeiro e Santa Catarina.

Para atender às novas exigências do Estatuto, uma nova versão do Sinarm está sendo desenvolvida pelo Sistema de Processamento de Dados do Governo Federal (Serpro) e sua implantação está prevista para acontecer nove meses após a assinatura do contrato com a Polícia Federal, processo esse ainda em negociação.

A razão para criar-se um novo Sinarm teve como diagnóstico que o atual sistema ainda é processado em plataforma alta (Mainframe) e em banco de dados Adabas, que são tecnicamente superados: isso significa que os custos para a implementação das modificações necessárias para atender às disposições do Estatuto do Desarmamento justificam o investimento em um novo sistema. 


\section{Estrutura}

A transferência de todo o sistema de controle de armas para a Polícia Federal, que antes era da alçada das secretarias estaduais de Segurança Pública, exige também a formação de uma equipe própria na esfera federal.

De acordo com as principais autoridades que chefiam o Sinarm (entrevistadas por uma equipe de pesquisadores que participaram desta pesquisa), em março de 2004 havia só cinco funcionários que cuidavam apenas do porte federal. Segundo as autoridades, para se operar eficientemente o Sinarm seria necessário no mínimo o triplo de funcionários e equipamentos, entre outros aspectos relacionados à infra-estrutura.

Para ilustrar a carência de pessoal, observamos que o registro de uma arma pode demorar muitos meses, às vezes anos. Com essa demora, muitos acabam desistindo da compra legalizada, o que leva à comercialização de armas e munições sem autorização.

As atividades dos técnicos ficaram ainda mais sobrecarregadas com a necessidade de se registrar as armas entregues na campanha do desarmamento, que até julho de 2005 somavam 374.878 .

Uma alternativa para superar essa carência de mão de obra especializada seria o estabelecimento de convênios com os órgãos de segurança pública dos estados. Todavia, em razão de disputas políticas e partidárias não houve interesse ora do Ministério da Justiça ora dos estados em celebrar convênios estaduais para a operação do Sinarm, apesar de alguns estados, como São Paulo, terem capacidade para tal. Dessa forma, a estratégia adotada foi a de, paulatinamente, descentralizar a operação para as próprias unidades estaduais da Polícia Federal ${ }^{7}$. Num sentido mais amplo, há uma grande expectativa de que o Sistema Único de Segurança Pública (SUSP) possa permitir uma maior integração e homogeneização nacional em termos de políticas orgânicas de segurança pública, tendo a União como agente estimulador.

Quanto ao financiamento do Sinarm, a Polícia Federal recebe taxas por expedir passaportes, e também por autorizar empresas de segurança privada e transporte de produtos químicos.

\footnotetext{
${ }^{7}$ Observamos aqui a interpenetração entre sistema político e políticas públicas. No caso, trata-se de uma interface negativa, pois as questões político-partidárias influenciaram na tomada de decisão e no emperramento do cumprimento da mesma, ao menos em alguns estados. Assim, a lógica partidária se sobrepôs, ao menos aparentemente, a uma decisão de longo prazo no campo das políticas públicas.
} 


\section{Processo e Sistema}

A alimentação inicial do Sinarm dependia das informações em posse dos estados. De acordo com técnicos da Polícia Federal, entre 1997 e 2003 algumas secretarias estaduais de Segurança Pública enviaram seus bancos de dados em arquivo eletrônico, mas muitas não enviaram nada. Mesmo aquelas que enviaram não o fizeram na íntegra, pois, além do envio parcial, seus registros estavam bastante incompletos, em contraste à diretriz federal de alimentar o sistema com informações as mais completas e fidedignas possíveis.

A partir de 23 de junho de 2005 estabeleceu-se que deveriam ser preenchidos todos os campos (do formulário eletrônico) possíveis; antes disso, muitos campos não eram de preenchimento obrigatório (inclusive o CPF) e cada estado tinha seus próprios campos obrigatórios.

Hoje o foco é a renovação dos registros, pois os proprietários com registros estaduais têm até o dia 2 de julho de 2007 - portanto três anos após a regulamentação do Estatuto - para passar seu registro para o nível federal; se não o fizerem, tornam-se ilegais.

Observamos que, até esse momento (cerca de um ano e meio após a aprovação do Estatuto), 99\% das renovações de registros provêm dos próprios policiais da PF, Polícia Civil, Polícia Militar e guardas municipais, já que eles têm o direito de registrar até 2 armas por policial sem pagar nenhuma taxa. Do ponto de vista do gerenciamento do sistema, tratase de uma informação altamente relevante, pois demonstra que a grande parte dos usuários comuns não está cadastrada: trata-se de uma constatação crucial à avaliação do Sinarm como gerenciamento do estoque de armas.

Quanto ao certificado de registro que é emitido pelo Sinarm, observamos que são frágeis os mecanismos de segurança; trata-se de uma folha de sulfite simples, recortada, o que a torna, portanto, um documento de fácil imitação. Uma outra fragilidade constatada refere-se à senha de usuário do Sinarm, considerada facilmente “quebrável” por usuários malintencionados (a senha é curta, de apenas quatro dígitos, e sem mesclar letras, números e caracteres especiais, por exemplo). Conclui-se ser necessária a introdução de senhas mais sofisticadas, assim como marcas d’água nos certificados, além de outros mecanismos, tais como os utilizados na emissão de papel moeda. É importante ressaltar que há inúmeros instrumentos de segurança conhecidos e que sua utilização aumentaria fortemente a credibilidade do Sinarm: trata-se de uma constatação da pesquisa.

CADERNOS GESTÃO PÚBLICA E CIDADANIA, V. 11, N. 48 - JAN/JUNHO 2006 
Quanto aos fabricantes de armas, estes enviam um arquivo padronizado para a PF. Este registro permite saber quais armas foram para as lojas e quais foram fabricadas para exportação. A chave dos registros é composta pelo número da arma, espécie, marca e país de fabricação: é importante notar que não basta haver apenas o número da arma, pois cada fabricante tem o seu próprio sistema de numeração, o que significa que pode existir - no limite - um mesmo número de arma para fabricantes diferentes. O controle da munição, por seu turno, é de competência do Comando do Exército e é regido pela portaria 40/MD/2004 do Ministério da Defesa. Uma vez mais se constata a necessidade de melhoria nos mecanismos de controle, agora por meio da padronização numérica, a ser definida pela PF e utilizada pelos fabricantes, pois afeta diretamente a credibilidade do Sistema como um todo. É importante ressaltar que há registros de armas encontradas com numeração duplicada (mesmo número de arma de um mesmo fabricante): uma parte legalmente adquirida no Brasil, outra ilegal do Paraguai, por exemplo. Essa situação gera problemas quando uma pessoa tenta registrar uma delas legalmente, casos dos períodos de anistia. E isso em se tratando de uma grande empresa, caso da Taurus, que é a maior fabricante nacional.

Em relação ao raiamento das armas e das microranhuras que ficam nas balas, nas entrevistas realizadas as autoridades do Sinarm afirmaram que nenhum país conseguiu superar a questão da inserção no sistema de controle das informações sobre os mesmos. Hoje isso não é feito, pois a microranhura pós-fabricação é uma e após dez disparos tornase outra; além do mais, criminosos jogam areia no cano e a disparam para alterar o que pode ser definido como o "DNA das armas". Também aqui se constata a necessidade de incrementar mecanismos de controle com vistas a, senão impedir, minimizar a adulteração do raiamento.

\section{O Controle Sobre as Empresas de Segurança Privada}

As autoridades salientaram que as empresas de segurança privada são as mais fiscalizadas no país. Estas empresas seriam as mais interessadas na aprovação da proibição do comércio de armas, pois diminuiria fortemente o número de “capangas” e de empresas ilegais de segurança. Aumentaria assim a demanda pela contratação de empresas de segurança privada legalizadas. É importante observar que as Delegacias Regionais do Trabalho 
fornecem o número individual de cada vigilante, a partir do Curso de Formação do Vigilante. São cerca de 1,1 milhão de vigilantes formados e, destes, cerca de 350 mil trabalham para empresas de vigilância (os demais procuram o curso para se tornar “empregáveis” no setor) e têm o direito de portar armas durante as atividades profissionais. Apesar desse contingente de vigilantes contratados, entre $70 \%$ e $80 \%$ andam armados, mesmo que não estejam vinculados às empresas de segurança.

A atividade de vigilância privada tem uma legislação própria desde 1983, quando foi sancionada a Lei 7.102, regulamentada no mesmo ano pelo Decreto 89.056. Apesar de existir um porte específico para os vigilantes, observa-se que muitas das polícias estaduais desconhecem essa lei e os prendem, pois entendem que não são possuidores do porte “comum”, dado que as armas não são de sua propriedade, mas das empresas de vigilância. Dessa forma, os vigilantes não poderiam ser presos porque têm direito ao porte, mas não têm um documento que ateste este porte, tal como os outros civis. Trata-se de uma indefinição ao mesmo tempo jurídica e administrativa que necessita ser dirimida urgentemente, pois, além do mais, propicia discriminações.

Quanto à escolaridade dos vigilantes, em 1995 houve uma nova portaria do Diretor Geral da PF ( $n^{\circ}$. 992) que estabeleceu que a escolaridade mínima deveria ser a $4^{\mathrm{a}}$ série do $1^{\circ}$ grau. Antes de 1983 essa formação mínima não era necessária e, em razão disso, ainda há muitos na ativa que não têm esta formação, e alguns são analfabetos. Com esta qualificação mínima e a formação específica, os vigilantes estariam aptos a desempenhar atividades como escolta armada, transporte de valores e segurança privada (guarda-costas).

O setor de vigilância privada possuiu um sistema próprio de controle, o Sistema de Vigilância Privada (SISVIP), que é alimentado com as informações do Sinarm. As autoridades apontaram uma fragilidade do mecanismo, isto é, a defasagem na informação que chega ao Sinarm, pois muitos eventos se perdiam no caminho interno da PF antes de chegar ao Sinarm (ex.: um aviso de roubo ou furto de arma, comunicado à PF estadual, até chegar ao Sinarm, em Brasília, poderia ser arquivado erroneamente, ou demorar a chegar até o sistema). Consideramos essa atualização dos eventos um aspecto crucial para a confiabilidade do sistema, o que implica a necessidade de desenvolver metodologias de alimentação do sistema que o torne efetivamente credível e eficaz. 
Como se observa, a pesquisa demonstrou inúmeras fragilidades na estrutura e na gestão do Sinarm, sobretudo vinculadas à confiabilidade dos dados: alimentação de informações nos estados; gap de tempo entre o registro nos estados e seu armazenamento no Sinarm, em Brasília; frágeis mecanismos de controles (senhas e afins); extremo simplismo do Sinarm como banco de dados; entre outros aspectos. Com isso, como discutiremos mais abaixo, as próprias políticas públicas ficam comprometidas tendo em vista a relativa disfuncionalidade da gestão do sistema legal de armas.

\section{A Utilização do Sinarm nos Estados e Municípios}

Na seccional de São Paulo ${ }^{8}$, as autoridades e técnicos nos informaram que utilizam o Sinarm fundamentalmente para consultas e consideram o sistema de fácil compreensão e operação; entendem também ser acertada a centralização promovida pela PF. Nesse sentido, é importante ressaltar que, historicamente, todos os países que implantaram fortes controles de armas o fizeram em regime de centralização em nível federal, tais como o Canadá, a Austrália e a Grã-Bretanha (a exceção é a França, em razão da própria estrutura federativa daquele país, em que os departamentos têm autonomia, inclusive policial, diferentemente do que se pensa, embora esta assertiva seja válida mais especificamente para Paris).

Há expectativa de que, com o recadastramento obrigatório dos proprietários de armas até julho de 2007, tanto as falhas de digitação como as informações sobre armas e proprietários - até então constantes nos antigos cadastros das secretarias estaduais de Segurança Pública, de forma precária, ressalte-se - sejam respectivamente corrigidos e colocados no sistema.

A campanha pelo desarmamento terminou no dia 23 de outubro de 2005 apenas para as armas ilegais (isto é, as que não se podiam comprovar procedência legal ou não tinham registro), mas continua para as legais e também para as irregulares (as que têm registros antigos ou vencidos e que se podem comprovar a procedência legal). Para as legais e irregulares há controvérsias sobre a possibilidade de os proprietários poderem entregá-las e ainda receberem a indenização, dado não haver prazo de vencimento para tanto. Notamos a

\footnotetext{
${ }^{8}$ Foi escolhida por ser a principal seccional do país.
} 
necessidade dos gestores federais e estaduais fazerem campanhas maciças com o objetivo de esclarecer os portadores de armas que ainda não se recadastraram.

Observamos também, in loco, as falhas no sistema (utilização do Sinarm na seccional de São Paulo) por não possibilitar um preciso registro do histórico de eventos envolvendo armas e proprietários. Em certas situações, para se atualizar um registro são perdidos os antecedentes que constituem o histórico da arma e do proprietário. Os técnicos também apontaram, no Sistema, a inexistência de notas e comentários sobre as razões das alterações dos registros, ou seja, o Sistema informa que foi feita uma determinada alteração e qual funcionário a fez, mas não o porquê e em quais circunstâncias. Notamos então a necessidade de novos campos que historicizem o percurso das armas (além de outras informações sobre os proprietários).

Por outro lado, o Sinarm não interage com outros bancos de dados ou outros meios de atualização, o que prejudica a veracidade e confiabilidade de seus registros. Por exemplo, caso o proprietário de uma arma venha a falecer, o Sistema, para se manter atualizado, depende da comunicação da família à polícia, ou, se o proprietário revender a arma a outra pessoa, esta, ao procurar a Polícia Federal, é quem deve informar sobre este evento. É importante observar que, para se proceder a esta atualização (sobretudo quanto aos óbitos) bastaria à PF averiguar periodicamente os bancos de dados de óbitos do Ministério da Saúde. Falta aqui claramente uma simples articulação entre banco de dados do Estado, pois denotaria integração entre políticas públicas.

Além do mais, o atual Sistema não possui consistência ou filtro interno de entrada de dados e nenhum critério de uso de caracteres. Por exemplo, se uma arma for cadastrada com o número de série 1234567 e depois for alterado para 1.234.567, o Sistema entenderá que são duas armas do mesmo proprietário. Nota-se claramente a ausência de padronização dos registros, o que poderia ser facilmente resolvido com a criação de um "protocolo de procedimentos”, como já havíamos detectado na visita ao próprio Sinarm em Brasília.

Para os operadores do Sistema que têm senha com autorização para atualizações de registro, executá-las é uma tarefa relativamente simples, e de forma geral podem fazê-las para qualquer registro de armas ou proprietários; mesmo para aqueles pertencentes a outras unidades da federação, basta entrar com o nome do proprietário ou o número de série da 
arma que os registros aparecem e podem ser alterados. Tais atualizações, contudo, não historicizam os eventos, como ressaltamos.

Apesar de o Sistema registrar quem alterou, fica a questão sobre a segurança dos dados e, no limite, a impossibilidade de se evitar uma sabotagem ou alteração deliberada de dados. Mais uma vez, é fundamental aqui que se desenvolvam metodologias e/ou procedimentos capazes de aumentar a segurança do sistema, sobretudo a verificação pelos supervisores, mesmo que por amostras, dos registros anotados pelos técnicos.

Segundo os técnicos, há campos que são alterados facilmente e outros não. Em muitas situações, o mesmo tipo de campo aparece na cor verde e pode ser alterado e às vezes aparece em branco, mas não é possível mudá-lo, mesmo quando é necessário. Nesses casos, faz-se um pedido aos técnicos que administram o Sistema no Centro de Processamento de Dados em Brasília. Também foram apontadas situações em que um erro é cometido na tela de registro, mas não pode ser corrigido no mesmo instante, e sim apenas posteriormente. O ideal é que se possam corrigir imediatamente eventuais erros cometidos.

Os técnicos relataram que o Sistema sofreu alterações no início de 2005 para se adaptar ao Estatuto do Desarmamento e também para registrar armas entregues na campanha do desarmamento. Houve também uma diminuição do número de telas do Banco de Dados, sem a perda de funcionalidade, o que na visão dos técnicos foi muito adequado. Trata-se de uma medida positiva a destacar.

Na delegacia da Polícia Federal de Presidente Prudente (SP) ${ }^{9}$, a autoridade principal afirmou que a grande maioria das pessoas que possui armas (legais e principalmente ilegais) desconhece a legislação e, assim, não tem consciência da gravidade do delito que está cometendo. Sobre os casos de porte ilegal, ressaltou que a legislação anterior à Lei 9.437 de 1997 era o Decreto Lei 3.688 de 1941 que definia o porte ilegal de arma como um delito simples para o qual cabia uma pequena detenção ou pagamento de multa de pequeno valor. A legislação de 1997 elevou o ato a crime com até dois anos de detenção e multa e, recentemente, com a legislação de 2003, a crime inafiançável.

Para o delegado-chefe, a quase totalidade dos proprietários de armas, mesmo das legais, não está preparada psicologicamente e muito menos habilitada para atirar, o que implica

\footnotetext{
${ }^{9}$ Esta cidade se justifica em razão do grande número de conflitos fundiários.
} 
destreza de manuseio da arma: isso compromete a eficiência do uso de armas (opinião que difere das autoridades da seccional da PF de São Paulo, de outros delegados e do setor de testes psicológicos ${ }^{10}$ ).

Ainda sobre o porte de armas, o delegado-chefe esclareceu que o proprietário de arma que solicita o porte é submetido ao exame da legislação, prova técnica sobre armamento, prova de destreza no uso da arma e finalmente a uma avaliação psicológica feita por psicólogos que usam metodologia composta por questões e baterias de testes desenvolvidos pelo pessoal do departamento de psicologia do Sinarm em Brasília. O cadastramento dos profissionais da área de psicologia ocorre em nível estadual, mas os mesmos são selecionados, treinados e fiscalizados pelo pessoal de Brasília.

Quanto à guarda das armas, nota-se que a legislação de controle de armas não prevê aonde o proprietário possa deixá-las quando tiver de se ausentar de sua residência por um longo período, quadro que se agrava quando o proprietário sem porte (a grande maioria dos casos), ao não ter permissão para carregar a arma, tem de deixá-la em casa, sendo freqüente os casos de residências em que há furto de armas.

Quanto ao procedimento para a aquisição de arma de fogo, é iniciado na loja de arma que fornece o formulário do Sinarm a ser preenchido pelo interessado. O formulário é então enviado à Delegacia da Polícia Federal mais próxima, onde é aberto um processo (por meio impresso), que por sua vez é enviado à Superintendência Estadual (no caso, São Paulo), onde é analisado: esses dados alimentam o Sinarm, assim como são averiguados no próprio Sinarm. Caso não haja impedimento legal, o interessado receberá a aprovação do pedido, sendo-lhe enviado o certificado de propriedade com o qual poderá solicitar à Polícia Civil uma guia temporária de trânsito para levar a arma da loja até à sua residência.

A partir de 2003 têm sido registrados casos de transferência de armas de um proprietário para outro ou casos de uso do período de anistia para os que conseguiram comprovar a origem legal da arma (geralmente casos de doações ou herança).

\footnotetext{
${ }^{10}$ Quanto aos testes psicológicos realizados com os portadores de armas, foram entrevistadas as três psicólogas responsáveis pelo departamento de avaliação psicológica do SINARM e que descreveram o trabalho recente de reavaliação e recadastramento do corpo de psicólogos encarregados da aplicação dos testes e de outros procedimentos de análise psicológica necessários para a liberação tanto dos certificados de posse como dos portes de armas. Para elas, os mecanismos tanto de averiguação da capacidade psicológica dos portadores de armas como do treinamento de psicólogos nos estados apresentam-se satisfatórios. Não foi possível, contudo, acompanhar in loco os treinamentos e revalidações. $\mathrm{O}$ tema mostrou-se controverso.
} 
Apesar de Presidente Prudente ser uma região de conflito fundiário, são raros os casos de apreensão de armamento ilegal nas fazendas. Desde 2000 ocorreram apenas dois casos, embora as razões para tanto como o real estoque de armas (sobretudo as ilegais) em regiões com esse perfil precisem ser melhores analisadas, pois aparentemente demonstram a fragilidade do sistema geral de controles de armas no país, dado tratar-se, reitere-se, de uma região extremamente conflituosa entre grandes proprietários de terras e trabalhadores sem terra.

Com relação ao uso do Sinarm, tanto o delegado-chefe como os agentes que interagem com o Sistema declararam ser o mesmo de fácil operação, pois está conectado à rede federal de transmissão de dados - o que assegura rapidez nas respostas -, e os casos de queda do Sistema (permanência fora do ar) por muito tempo não são freqüentes. Portanto, naquilo que demandam do Sistema estão plenamente satisfeitos.

O único problema apontado não é com o Sistema, mas com as informações que constam do mesmo; por exemplo, os casos de duplicação de numeração de armas e a ausência de informação de armas cadastradas nos antigos sistemas estaduais, como é o caso de armas que, apesar de cadastradas pela polícia de outro estado, tendo sido furtada em São Paulo, não constam no Sinarm: esses casos são freqüentes em todas as unidades federativas do país e apenas corroboram a fragilidade do Sinarm como Sistema de gestão.

É interessante ressaltar que, quanto às indenizações aos ex-proprietários que entregaram suas armas na campanha do desarmamento, houve reclamações quanto à demora do governo no pagamento das mesmas. Nesse sentido, a campanha do desarmamento trouxe um ônus extra para as delegacias descentralizadas e de um modo geral para toda a Polícia Federal, pois tiveram que destinar os já poucos funcionários e recursos para organizar a campanha e atender aos cidadãos. Das armas recolhidas na Delegacia de Presidente Prudente, 80\% não estavam em condições de uso; mesmo assim os proprietários foram indenizados.

Até a legislação de 2003, muitas delegacias de Polícia Civil estaduais tinham terminais de consulta ao Sinarm, mas com a nova legislação a Polícia Federal os retirou e implantou postos de plantão (24 horas por dia) nas 83 Delegacias da Polícia Federal, também denominadas descentralizadas, para a consulta pelo pessoal da Polícia Civil e da Polícia Militar. 
Em relação à delegacia descentralizada de Foz do Iguaçu (PR) ${ }^{11}$, o delegado-chefe destacou que o Sistema funciona em plataforma DOS e que não apresenta problemas de queda ou lentidão; é considerado por ele como um Sistema estável e confiável em termos operacionais. Ressaltou que, apesar de Foz do Iguaçu ser a segunda maior delegacia em apreensões de armas no Brasil - São Paulo é a primeira -, da mesma forma que as demais delegacias descentralizadas faz (em Foz de Iguaçu) apenas consultas e não atualiza nenhum dado no Sistema. Qualquer necessidade de atualização ou inclusão é solicitada, via processo ou ofício, à Superintendência Estadual em Curitiba. Entendemos que esse procedimento necessita ser alterado, pois a atualização é tão ou mais importante do que a alimentação de ocorrências originais de registro. Destacamos, portanto, que um gerenciamento mais eficaz do Sistema deve conferir atenção especial ao quesito “atualização”. Possivelmente, por meio de senhas especiais e de averiguação amostral por parte das superintendências regionais, a atualização possa ser mais efetiva, conferindo ao Sistema a confiabilidade e a atualização necessárias ${ }^{12}$. É importante ressaltar como essa questão está presente em todas as delegacias e, portanto, pauta a discussão do gerenciamento do Sinarm.

Também aqui os agentes usuários do sistema afirmaram que grande parte das informações dos cadastros das polícias civis estaduais, que foram alimentadas no Sinarm, após sua criação em 1997, se encontrava desatualizada, incompleta ou mesmo equivocada, e que esse problema perdura até hoje, apesar dos constantes esforços de correção da informação pelas unidades e usuários. Contudo, essas correções dependem da ocorrência de algum evento envolvendo armas (apreensão) ou da demanda do proprietário ao Sistema, ocasiões em que se percebe o erro cadastral ou mesmo a ausência deste. Por exemplo, um proprietário pode ter adquirido legalmente uma arma que foi cadastrada no antigo sistema estadual, no caso o da Polícia Civil do Paraná, mas estes dados não terem migrado para o Sinarm.

\footnotetext{
${ }^{11}$ Estratégica em razão da fronteira com o Paraguai, devido, sobretudo, aos casos de contrabando na região.

${ }^{12} \mathrm{O}$ técnico que atendeu os pesquisadores disse que, apesar de uma breve palestra de apresentação sobre o Sistema quando de sua formação na Academia de Polícia Federal em Brasília, não teve nenhum curso específico ou mesmo acesso a algum material didático sobre o assunto. Contudo, salientou que não teve nenhuma dificuldade em lidar com o Sistema, fato que confirma a simplicidade e facilidade de interação com o Sinarm, o que é um dado bastante positivo, reitere-se.
} 
Outras informações que ainda não estão no Sistema são relativas às armas das polícias que são de calibre restrito e que por esta característica constam ainda apenas no Sistema de Gerenciamento Militar de Armas (Sigma), administrado pelo Comando do Exército. A interligação entre este sistema e o Sinarm estava prevista para acontecer em até um ano após a publicação da lei que regulamentou o Estatuto do Desarmamento, ou seja, até 2 de julho de 2005 - o que não pode ser observado na prática.

Para os que operam o Sistema em Foz do Iguaçu, o fato de haver centralização das atualizações e alterações de informações apenas em Curitiba provoca duas implicações: a positiva é a garantia de que as modificações são feitas apenas em um ponto; a negativa é que isso sobrecarrega a Superintendência Estadual, pois o pessoal tem de atender o estado inteiro e também imprimir e enviar os certificados dos registros de armas.

Em relação à delegacia da PF de Campinas $\mathbf{( S P )})^{13}$, as principais atividades relatadas pelas autoridades referem-se à orientação aos interessados em possuir porte de armas: documentos necessários, formulários, valores das taxas etc. Quando se inicia o processo de registro, verifica-se a documentação, expede-se o protocolo e posteriormente enviam-se esses documentos para a Superintendência Estadual. Como dissemos, a unidade da capital é a responsável pela inserção dos dados no Sinarm e pela geração do número de registro.

A unidade de Campinas, assim como as demais do interior, tem apenas acesso ao banco de dados por meio de senha. De acordo com o delegado-chefe, apenas ele e mais um agente são os responsáveis pelo Sinarm na unidade. Da mesma forma que em outras unidades, fomos informados que o Sistema não apresenta dificuldades de manuseio e que a rede é confiável do ponto de vista das informações processadas.

A senha (também de quatro dígitos) tem prazo de validade e o próprio Sistema informa ao usuário quando está expirando, o que é um aspecto positivo do Sistema, pois denota um item de segurança. O Delegado-chefe não soube informar, contudo, a periodicidade em que deve ser realizada a troca da senha.

\footnotetext{
${ }^{13}$ Cidade importante por ser a segunda maior depois da Capital do estado de São Paulo, com diversas implicações, sobretudo quanto aos índices de criminalidade.
} 
Em caso de roubo ou furto de arma, a Polícia Civil faz a notificação para a Delegacia da PF de Campinas que, por seu turno, informa à Superintendência estadual, responsável por atualizar o Sinarm.

O delegado-chefe relatou uma experiência própria que exemplifica as falhas estruturais do Sinarm, isto é, a falta de atualização dos dados do Sistema. Ele teve uma arma furtada há cerca de quatro anos e, além do Boletim de Ocorrência, solicitou que o furto fosse registrado no Sistema. Entretanto, ainda hoje o Sinarm registra a arma em seu nome. Foi preciso enviar um ofício à Superintendência, com cópia do B.O., solicitando a atualização. Este episódio, em se tratando de um delegado da própria PF, demonstra apenas como para o cidadão comum - para o qual o Sistema deve funcionar - o Sistema ainda é pouco credível.

\section{O Referendo sobre o Desarmamento}

Durante toda a fase de elaboração da pesquisa o país viveu um intenso debate em torno do referendo sobre o desarmamento que decidiria pela proibição ou não do comércio de armas e munições. As autoridades federais apontaram uma questão importante e que não foi tratada durante a elaboração do Estatuto do Desarmamento: a diferença entre armas de cano longo e de cano curto. Declaram-se favoráveis à proibição da venda de armas de mão (de cano curto e baixo calibre) a civis, mas, quanto às armas longas, em razão de seu objetivo principal ser a proteção pessoal em locais específicos do país (proteção contra animais selvagens no Pantanal, na Amazônia etc.), não causariam problemas para a segurança pública, e, portanto, sua proibição seria desnecessária e poderia ter sido excluída do referendo. Teria havido, portanto, uma generalização desnecessária da proibição, gerando, com isso, perda parcial de legitimidade do Estatuto do Desarmamento: possivelmente esse seria também mais um dos motivos para a derrota estrondosa do “sim” no referendo.

Observamos, por seu turno, que, caso fosse aprovada a proibição do comércio de armas e munições, o departamento responsável pelo combate ao tráfico de armamentos seria mais pressionado em razão da expectativa de aumento do tráfico ilegal.

Ao analisarmos o contexto mais amplo do controle de armas no Brasil, pode-se interpretar que parte das razões da vitória do "não" no referendo sobre a proibição do comércio de armas realizado em outubro de 2005 deve-se à descrença nas instituições, notadamente as 
relativas aos sistemas judiciário, policial e de controles (em sentido amplo, o que perpassa os próprios controles sociais). Nesse sentido, é importante ressaltar a falta de uma "cultura do controle de armas” tanto pelo cidadão comum como, especialmente, pelo Estado. Tratase, portanto, de um ambiente cultural - no sentido da "cultura política” - mais amplo que nos ajuda a compreender parte dos motivos de o Brasil ser recordista em número de assassinatos por armas de fogo. A avaliação do funcionamento do Sinarm constitui, nesse sentido, um aspecto crucial para transformar essa realidade, em razão tanto da efetividade dos controles das armas de fogo como da percepção da sociedade sobre tais controles. Nesse sentido, a gestão da informação, representada pelo Sinarm, deve entrar na pauta como prioridade em termos de políticas públicas de Segurança Pública, pois a relação entre ambas é inequívoca.

Comparativamente aos sistemas de outros países - notadamente o australiano, o canadense, o inglês e o francês -, observa-se que os dilemas quanto ao maior controle e rigidez pelo Estado versus a concepção do “direito a possuir armas” faz parte da tradição anglosaxônica. Em grande medida por causa de tragédias que ocorreram com armas de fogo é que estas sociedades se mobilizaram, transformando suas legislações, o que implicou a centralização e normatização do uso de armas. No caso francês, nota-se a autonomia dos departamentos em conceder ou não licenças e portes de armas, mas submetidos à legislação federal.

Quanto ao Brasil, não foram tragédias específicas que mobilizaram a sociedade e sim a constatação de que se vive no país uma “guerra civil permanente”, a ponto de em 2004 cerca de 36.000 pessoas terem perdido a vida por armas de fogo. O sistema brasileiro de registro era, até 1997, descentralizado nos estados, situação que vem progressivamente se alterando desde a criação do Sinarm e, sobretudo, a partir de 2004, com a elaboração do Estatuto do Desarmamento. Nos outros países não foi observado o problema da falta de recursos para desenvolver o sistema de controle de armas, questão fundamental havida no Brasil.

Em relação à “cultura política” (valores que uma sociedade confere a temas referentes à esfera pública, em diversas dimensões), embora a questão do “direito a ter armas” tenha aparecido com maior vigor no Brasil somente em 2005, em razão do referendo sobre a proibição de comércio de armas e munições, há um ambiente propício à existência de 
armas, cujos componentes são: descrença nas instituições (reitere-se), sensação de impunidade, frágeis controles técnico-institucionais sobre o controle de armas (caso, como apontado, dos registros esparsos e pouco padronizados das secretarias estaduais de segurança e das dificuldades de implantação do Sinarm), ausência de preocupação das próprias autoridades com um Sistema nacional, entre outros.

Todas essas dificuldades vêm sendo combatidas, embora lentamente, pois há maior mobilização da sociedade organizada e também de agências estatais e universidades públicas - casos respectivamente de diversas ONGs voltadas ao tema violência/segurança e de centros de pesquisa vinculados às grandes universidades estaduais e federais, que recentemente vêm se ocupando desses temas e produzido estudos de grande importância, entre outras ações -, assim como certa consciência coletiva de que algo deve ser feito para combater a violência no país. Do ponto de vista institucional, o Sinarm pode vir a contribuir significativamente não apenas para o registro de dados brutos sobre armas, mas, sobretudo, com sua articulação a políticas públicas mais amplas de segurança, como aludimos. Apesar de limitada ao estoque legal, a historicidade dos eventos ocorridos com as armas registradas - como furtos, recuperação da arma, adulteração etc - pode permitir o conhecimento sobre o fluxo de armas no país, que transita da legalidade à ilegalidade de forma contínua: este é um dos aspectos mais relevantes do debate sobre o controle de armas no Brasil, pois parte significativa de seu estoque ilegal tem origem legal - atestado pelo recente relatório da CPI do Tráfico de Armas. O atual Sinarm, contudo, não permite tal historicidade, o que é claramente uma falha importante a ser corrigida, conforme apontamos.

\section{O Sinarm como Estrutura Gerencial: Problematização e Conclusões}

A pesquisa concluiu que o Sinarm necessita ser tecnicamente melhorado - o que implica o aporte de recursos humanos e técnicos não apenas na sede como nos estados da federação, e também nas cidades em que há delegacias da PF, além da maior sofisticação de seus registros - como forma de mostrar-se confiável e mais seguro de modo sistêmico. A articulação entre a sede em Brasília, as seccionais (regionais) e as cidades é, portanto, um elemento chave para o sucesso do Sinarm. Também a migração de informações de todos os bancos de dados das polícias civis estaduais, por mais precários que sejam, assim como sua padronização, representam ações fundamentais. Apesar dos problemas observados, 
consideramos tratar-se de um avanço a sua criação em 1997 e, sobretudo, a aprovação do Estatuto do Desarmamento. A centralização na PF dos registros também é positiva, sobretudo tendo em vista as realidades regionais e locais no país, muitas vezes marcadas pela baixa institucionalização do Estado de Direito; contudo, as dificuldades financeiras têm trazido grandes transtornos quanto a esse objetivo. Também se observou o endurecimento de regras (por meio da legislação) para quem pretende possuir armas, o que é bastante positivo num país em que as armas de fogo matam mais do que os países oficialmente em guerra civil.

Quanto às conclusões mais gerais do desempenho do Sinarm, conjugadas ao Estatuto do Desarmamento, podem ser sintetizadas da seguinte forma:

a) Há carências de recursos materiais e humanos, reitere-se, aspecto fundamental, sobretudo na sede da Polícia Federal em Brasília, em razão do não suprimento de pessoal e de computadores em quantidade adequada e também em razão do espaço físico ser pouco adequado.

b) O Sinarm não completou a absorção das informações de todos os sistemas estaduais, que são estruturalmente esparsos, com informações não padronizadas e com poucos registros - proporcionalmente ao universo de armas -, além de desatualizados, com algumas exceções, caso de São Paulo. Especificamente quanto à desatualização, uma importante conclusão advém do retorno dos questionários analisados pela pesquisa "Valores e Significados Atribuídos às Armas de Fogo por Cidadãos Proprietários e por Detentores do Porte de Armas”14, da qual participamos, conforme demonstra o quadro abaixo:

\footnotetext{
${ }^{14}$ Esta pesquisa objetivou analisar quais valores culturais sustentam a posição dos portadores legais de armas e foi avaliada por meio de um questionário.
} 


\section{Tabela 1}

Taxa de erro de cadastro e de retorno de questionários.

\begin{tabular}{c|c|cc|c|cc|cc}
\hline Estado & Enviados & \multicolumn{2}{|c|}{ Devolvidos (erro) } & Recebidos & \multicolumn{2}{c|}{ Respondidos } & \multicolumn{2}{c}{ Não retorno } \\
\hline & Qtd. & Qtd. & \% & Qtd. & Qtd. & \% & Qtd. & \% \\
\hline \hline ES & 750 & 113 & $15,1 \%$ & 637 & 141 & $22,1 \%$ & 496 & $77,9 \%$ \\
MT & 750 & 182 & $24,3 \%$ & 568 & 52 & $9,2 \%$ & 516 & $90,8 \%$ \\
PE & 750 & 147 & $19,6 \%$ & 603 & 49 & $8,1 \%$ & 554 & $91,9 \%$ \\
RJ & 750 & 68 & $9,1 \%$ & 682 & 53 & $7,8 \%$ & 629 & $92,2 \%$ \\
RO & 750 & 190 & $25,3 \%$ & 560 & 71 & $12,7 \%$ & 489 & $87,3 \%$ \\
RS & 746 & 165 & $22,1 \%$ & 581 & 69 & $11,9 \%$ & 512 & $88,1 \%$ \\
SP & 1.500 & 253 & $16,9 \%$ & 1.247 & 220 & $17,6 \%$ & 1.027 & $82,4 \%$ \\
\hline TOTAL & $\mathbf{5 . 9 9 6}$ & $\mathbf{1 . 1 1 8}$ & $\mathbf{1 8 , 6 \%}$ & $\mathbf{4 . 8 7 8}$ & $\mathbf{6 5 5}$ & $\mathbf{1 3 , 4 \%}$ & $\mathbf{4 . 2 2 3}$ & $\mathbf{8 6 , 6 \%}$ \\
\hline \hline
\end{tabular}

Fonte: Pesquisa sobre valores e significados dos proprietários e portadores de porte de armas.

Este quadro indica que, a partir de uma amostra aleatória, extraída do banco de dados do Sinarm com 6.000 proprietários de armas para os quais foram enviados questionários, 1.118 questionários (18,6\%) voltaram por erros cadastrais de endereço - endereço não existente, mudança de endereço do proprietário, entre outros motivos -, fato que indica a desatualização de uma parcela significativa dos endereços constantes no Sinarm.

c) Os processos de averiguação da real capacidade e habilidade dos portadores de armas em tê-las, particularmente a constância das averiguações, é um componente importante aos controles como um todo, embora não se refira especificamente ao Sinarm como Sistema. Causaram-nos boa impressão os controles realizados em relação às empresas de segurança privada e de transporte de valores, assim como os relativos aos profissionais de segurança privada, que respectivamente são fiscalizados com rigidez. São, nesse sentido, um exemplo do bom funcionamento do sistema federal de controle. O cidadão comum, contudo, não recebe o mesmo tratamento que esses referidos grupos, fundamentalmente em razão da atualização dos registros no Sinarm ${ }^{15}$.

d) A centralização ora em processo pela PF - centralização em relação às secretarias de segurança dos estados - vem dificultando sobremaneira os pedidos de registro e porte

\footnotetext{
${ }^{15}$ Quanto ao controle de munições, ele é realizado pelo Exército. Apenas após a aprovação do Estatuto do Desarmamento é que se tornou obrigatória a marcação do número do lote ao qual pertence cada unidade de munição.
} 
de armas, pois os solicitantes devem ir até à sede (seccional) da PF mais próxima, o que, em diversos lugares, implica grande distância, podendo, com isso, estimular a obtenção ilegal de armas. Nesse sentido, percebemos que há uma tensão entre a PF e algumas secretarias de segurança dos estados, notadamente São Paulo, tendo em vista que este estado possui - e possivelmente seja uma exceção - melhor estrutura do que a própria PF. A maior agilidade, sobretudo por meio de convênios entre entidades do Estado, nos três níveis, poderia ser uma solução para o problema da demora.

e) O Estatuto do Desarmamento está forçando o recadastramento de todos os proprietários de armas que ainda não estão registrados no Sinarm, embora o estejam nos seus respectivos estados, por meio dos antigos sistemas de controles estaduais (via secretarias de segurança pública). Tal medida aponta para o aumento progressivo de registros do número de proprietários, assim como da criação de um procedimento obrigatório quanto aos novos registros. Isso potencialmente implicará a revalorização do Sinarm, e também o aumento de suas responsabilidades: quanto maiores forem essas maiores cobranças ocorrerão dos usuários (cidadãos e autoridades).

f) Comparativamente aos outros países pesquisados (acima referidos), nota-se que o Sistema brasileiro caminha para a centralização, que vem ocorrendo desde a criação do Sinarm em 1997, e que se acentuou com a aprovação do Estatuto do Desarmamento em 2003.

g) O Estatuto do Desarmamento representa um marco no que tange ao controle de armas legais no país em razão das dificuldades legais impostas aos que pretendem obter armas, porte e mesmo a renovação deste (também as taxas para obtenção e renovação do registro e porte de armas foram aumentadas significativamente). Por outro lado, a não entrada de armas por meios ilegais dependerá em grande medida da rígida fiscalização das fronteiras e de outras medidas correlatas, que necessitam ser eficazes e, sobretudo, conjugadas às políticas de controle do estoque legal, sem o qual o Sinarm jamais conseguirá cumprir suas funções.

h) O Estatuto do Desarmamento permite, no longo prazo - sendo o Sinarm um componente fundamental -, a articulação com as políticas públicas de segurança, para além, portanto, de políticas tópicas, como historicamente se desenvolveram no Brasil. Nesse sentido, reitere-se o papel que paulatinamente poderá vir a desempenhar o 
Sistema Único de Segurança Pública (SUSP) nesse processo, isto é, semelhante ao Sistema Único de Saúde (SUS) no sentido de normatização e estímulo a ações conjugadas entre os estados. Dessa forma, Estatuto do Desarmamento e SUSP poderão ser vistos como complementares.

A partir desse diagnóstico, diversas ações poderiam melhorar o desempenho do Sinarm e dizem respeito à atualização dos dados e ao aumento da segurança e confiabilidade do Sistema como um todo, de forma orgânica. Sobretudo quanto à atualização dos dados, concluímos que é de fundamental importância o Sistema permitir - o que hoje não ocorre, reitere-se - a historicidade tanto da arma (sobretudo) como do proprietário da mesma, o que implica a existência de campos específicos no Sinarm que permitam anotar continuamente todas as ocorrências quanto a ambos, mas particularmente quanto às armas.

Mas é importante ressaltar, por outro lado, os avanços e pontos positivos proporcionados pelo Sinarm, que, por si só, representa um passo importante no controle de armas no Brasil, o que, por seu turno, poderá contribuir para a reversão da própria “cultura impune de armas” no país: um dos fatores responsáveis pelo elevado número de assassinatos com armas de fogo. A confiabilidade no Sistema pelo cidadão comum e pelas próprias autoridades - tendo em vista a dimensão continental do país - no Sistema de cadastro e gerenciamento de armas pode auxiliar no combate ao ambiente (que é também, embora não apenas) cultural, de impunidade que historicamente viceja no país. Isso no que diz respeito ao estoque legal de armas, nunca é demais reiterar. Portanto, a conjugação de políticas públicas de segurança no que tange tanto ao estoque legal - em que o Sinarm ocupa papel destacado - como ao ilegal é crucial à diminuição do número de crimes com armas de fogo, ao lado, é claro, da melhoria das condições sociais do País, marcado pela brutal desigualdade socioeconômica e de oportunidades, notadamente a ausência de perspectivas de vida aos jovens das periferias. A simplicidade de acesso e da operação do Sinarm, atestados por técnicos tanto da sede como das cidades pesquisada, demonstra ser o sistema “amigável” aos seus operadores usuais, o que é um aspecto bastante positivo. Afinal, as seccionais e cidades com delegacias da PF são a base de alimentação do Sistema e necessitam, por isso, de um banco de dados facilitador dos registros.

A pesquisa procurou analisar as virtudes e fragilidades do Sinarm - que ganha maior importância com o Estatuto do Desarmamento - numa perspectiva ao mesmo tempo ampla 
(o contexto da violência no país e as políticas públicas de segurança pública) e específica (o desempenho do Sinarm e sua transformação em banco de dados centralizado com capacidade gerencial eficaz e eficiente).

Especificamente quanto à Administração Pública, o Sinarm revela um conjunto de erros gerenciais e de gestão que necessitam ser evitados quando da instituição de Bancos de Dados de gerenciamento, pois geram incerteza aos usuários e dificultam a credibilidade e racionalidade tanto do Estado enquanto instituição como das políticas públicas advindas dele. O fato de o Sinarm não ter sido objeto de uma ampla maturação e sim de uma decisão tomada por poucos técnicos e delegados da PF certamente contribuiu fortemente para sua pouca permeabilidade.

Por fim, cabe refletir sobre o papel da gestão da informação pelo Estado, notadamente em um país com as dimensões, desigualdades (incluindo-se as federativas) e complexidades da sociedade brasileira. Trata-se de um tema que, embora venha ganhando espaço na agenda nacional, ainda está longe de ter se constituído de forma sistêmica. Impressiona ao analista observar que as guardas civis metropolitanas, as polícias civis, militares e a federal, além das próprias Forças Armadas - fundamentais à vigilância de fronteiras, portos e aeroportos -, não se comunicam eficaz e eficientemente por meio de um Banco de Dados único que registre pessoas com passagens criminais. A socialização de informações, o diálogo entre estes agentes públicos de segurança, e mesmo sua articulação com entidades como o Coaf (vinculado ao Banco Central e responsável pela fiscalização de operações financeiras, a chamada "lavagem de dinheiro”), entre outras, ainda não ocorre no Brasil de forma sistêmica. Por mais que haja avanços, falta muito para que a gestão de informações criminais (em sentido amplo) se processe de forma holística, sistêmica e, sobretudo, articulada. Nesse sentido, o Sinarm é apenas mais um aspecto dessa desarticulação, mas que, por meio do Estatuto do Desarmamento, implica progressivos avanços.

A pesquisa que este artigo expressa quis demonstrar os dilemas da gestão de informação pelo Sinarm - apesar de seu pouco tempo de existência -, porém numa perspectiva ampla, em que a gestão de informações seja pensada de forma articulada à capacidade de planejamento e, com isso, das políticas públicas. Sobretudo num momento em que a democracia política brasileira avança no sentido da transparência - apesar de seus inúmeros constrangimentos -, e em que organizações da sociedade influenciam as decisões estatais, o 
tema da gestão de segurança pública adquire maior visibilidade. E isso tanto pelo aludido ambiente de "guerra civil" que vivemos como pela consciência de que a universidade e a sociedade organizadas têm muito a contribuir, dado que "violência/segurança pública” é um tema da sociedade como um todo, não vinculado, pois, à tecnocracia ou exclusivamente aos aparatos militares, como historicamente o foi no Brasil. Portanto, a análise aprofundada da gestão da informação e do gerenciamento em sentido amplo das relações entre violência e segurança pública (em suas diversas dimensões) é fundamental à progressiva diminuição da violência e da perda de vidas no Brasil, sobretudo pelo uso indiscriminado de armas de fogo. Embora relacionadas a experiências mais complexas em termos de políticas de segurança pública, os exemplos exitosos do Jardim Ângela, na cidade de São Paulo, e da cidade de Diadema (aliás, única cidade do estado de São Paulo a votar majoritariamente pelo “sim” no referendo), demonstram que a articulação entre Estado e sociedade, em que a gestão da segurança é tomada como um problema coletivo a ser enfrentado, permite resultados positivos. Esta pesquisa, por meio da análise da gestão da informação representada pelo Sinarm, é uma amostra que comprova a necessidade de articulação sistêmica entre as diversas variáveis e atores que compõem o tema em foco. 


\section{Bibliografia e Fontes}

ABREU, Abel Fernando Marques. Armas de fogo. São Paulo: Iglu, 1999.

ADENAUER, Fundação Konrad. A Violência do Cotidiano. Cadernos Adenauer II (2001), $\mathrm{n}^{0}$ 1. São Paulo: Fundação Konrad Adenauer, 2001.

ARAÚJO Jr., Ruy. “Armas x criminalidade no Brasil”. IN: Revista Direito Militar, v.3, n.16, p.27-31, mar.-abr.1999.

AUSTRALIAN GOVERNMENT. Consultation draft: firearms safety training report. Disponível na WWW em: http://www.law.gov.au/publications/firesafety/safety1.html.

BARROS, Mari Nilza Ferrari de. “A identidade do Policial Militar: os dilemas presentes no contexto da corporação”. In: BARROS, Mari Nilza Ferrari de (org.). Itinerários em Psicologia Social. Londrina: Editora UEL, 2001.

BASTOS, Marcelo Lessa. “A medida provisória $n^{0}$. 229/2004 e o Estatuto do Desarmamento: retomando a questão da eficácia de seus arts. 12 e 14: posse irregular de arma de fogo”. IN: Boletim Ibccrim, v.12, n.147, p.9-10, fev.2005.

BUENO, Luciano. Controle de armas: um estudo comparativo de políticas públicas entre Grã-Bretanha, EUA, Canadá, Austrália e Brasil. São Paulo: IBCCRIM, 2004.

CALHEIROS, Renan. “Arma contra a violência”. IN: Tribuna do Brasil, Brasília, n.1014, 19/7/2004, p.A2.

CÂMARA DOS DEPUTADOS. Projeto de Lei da Câmara (PLC) $n^{\circ}$ 64/1996 que se transformou na Lei 9.437/1997 (Lei de criação do Sinarm).

CENTRO INTERNACIONAL DE INVESTIGAÇÃO E INFORMAÇÃO PARA A PAZ. $O$ Estado da Paz e a Evolução da Violência na América Latina - A situação da América Latina. Campinas, Editora da Unicamp, 2002.

CFC - CANADIAN FIREARMS CENTRE. History of firearms control in Canada. Disponível em: http://www.cfc.gc.ca/historical/firearms/firearms_control.html.

CGC - COALITION FOR GUN CONTROL. Gun control news 2000-2001. Disponível em: http://www.guncontrol.ca/Content/news.html.

CHAPPELL, D. A national gun control strategy: the recommendations of the National Committee on Violence. Canberra: Australia Institute of Criminology, 1992.

COOK, Philip J. Gun Control. Annals of the American Academy of Political and Social Science, v.455, may 1981. (226 p.)

DOTTI, René Ariel. A política de segurança pública e o estatuto do desarmamento. IN: Revista forense, v.101, n.377, p.151-68, fev.2005. 
HOME OFFICE. Controls on Firearms: A Consultation paper. Great-Britain: Home Office, Communication Directorate, 2004. Disponível em: http://www.homeoffice.gov.uk/docs3/controls_on_firearms.pdf.

JESUS, Damásio Evangelista de. "Porte de arma de fogo". IN: Correio Braziliense, Brasília, Cad. Direito e Justiça, n.14925, 29/3/2004, p.2.

KAHN, Túlio. Velha e Nova Polícia: Polícia e Políticas de Segurança Pública no Brasil Atual. São Paulo: Editora Sicurezza, 2002.

KOPEL, D. B. The samurai, the mountie, and the cowboy: should America adopt the gun controls of other democracies?. New York, Prometheus Books, 1992.

LIMA, Renato Sérgio de. "Também morre quem atira!: risco de pessoa que possui arma de fogo ser vítima fatal de um roubo”. IN: Revista Brasileira de Ciências Criminais, v.8, n.29, p.365-373, jan.mar.2000.

NFA - NATIONAL FIREAMRS ASSOCIATION. The NFA is the united voice of canadian firearm owners. Disponível em: http://www.nfa.ca.html.

NÓBREGA, Airton Rocha. "Vedação ao registro de armas de fogo e contenção à violência urbana”. IN: Informativo Jurídico Consulex, v.14, n.31, p.4-5, 31.jul.2000.

OLIVEIRA, Isaura de Mello Castanho e (org.); PAVEZ, Graziela Acquaviva (org.); SCHILLING, Flávia (org.). Reflexões sobre justiça e violência: o atendimento a familiares de vítimas de crimes fatais. São Paulo: EDUC, 2002.

OLTRAMARI, Alexandre. “A parábola das duas armas”. in Veja, v.36, n.39, p.48-50, 1.out.2003.

POVEY, D. Crime in England and Wales 2002/2003: Supplementary. Volume 1 Homicide and Gun Crime, 2004. Disponível em: http://www.homeoffice.gov.uk/rds/index.htm.

SADEK, Maria Tereza (org.). Delegados de Polícia. São Paulo: IDESP - Instituto de Estudos Econômicos Sociais e Políticos de São Paulo, 2002.

SCARFF, E. Firearms control in Canada: an evaluation. Ottawa: Ministry of the Solicitor General of Canada, 1981.

SENADO FEDERAL. Projeto de Lei do Senado (PLS) $n^{\circ} 292 / 1999$ que se transformou na Lei 10.826/2003 (Estatuto do Desarmamento).

SOARES, Gláucio Ary Dillon. "Matar e, depois, morrer”. IN: Opinião Pública, v.8, n.2, p.275-303, out.2002. 
SOARES, Luiz Eduardo. Meu Casaco de General: 500 dias no front da segurança pública do Rio de Janeiro. São Paulo: Companhia das Letras, 2000.

TEIXEIRA, João L. Vieira. Armas de fogo: são elas as culpadas? S. Paulo: LTr, 2001.

VELOSO, Fábio Geraldo. “Armas de fogo e prevenção de crimes”. IN: Boletim Ibccrim, v.9, n.110, p.6-7, jan.2002.

Artigo recebido em 31/10/2005 e aprovado em 15/12/2005 